
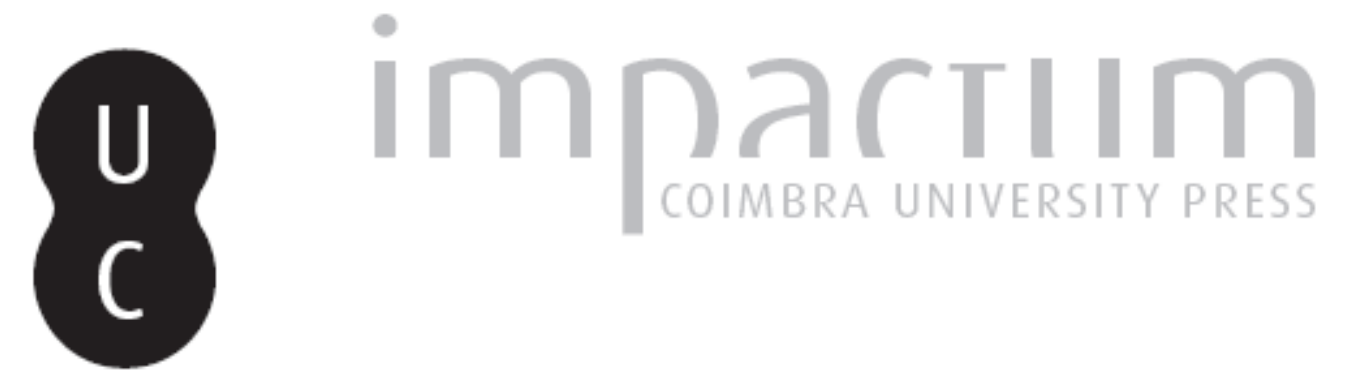

Autonomia regional y Estado Nacional en Mexico a mediados del XIX

Autor(es): $\quad$ Cerutti, Mario

Publicado por: Imprensa da Universidade de Coimbra

URL persistente:

URI:http://hdl.handle.net/10316.2/43800

DOI:

DOI:https://doi.org/10.14195/2183-8925_10_40

Accessed : $\quad$ 26-Apr-2023 08:46:04

A navegação consulta e descarregamento dos títulos inseridos nas Bibliotecas Digitais UC Digitalis, UC Pombalina e UC Impactum, pressupõem a aceitação plena e sem reservas dos Termos e Condições de Uso destas Bibliotecas Digitais, disponíveis em https://digitalis.uc.pt/pt-pt/termos.

Conforme exposto nos referidos Termos e Condições de Uso, o descarregamento de títulos de acesso restrito requer uma licença válida de autorização devendo o utilizador aceder ao(s) documento(s) a partir de um endereço de IP da instituição detentora da supramencionada licença.

Ao utilizador é apenas permitido o descarregamento para uso pessoal, pelo que o emprego do(s) título(s) descarregado(s) para outro fim, designadamente comercial, carece de autorização do respetivo autor ou editor da obra.

Na medida em que todas as obras da UC Digitalis se encontram protegidas pelo Código do Direito de Autor e Direitos Conexos e demais legislação aplicável, toda a cópia, parcial ou total, deste documento, nos casos em que é legalmente admitida, deverá conter ou fazer-se acompanhar por este aviso.

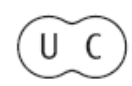


REVISTA DE HISTORIA DAS IDEIAS IO
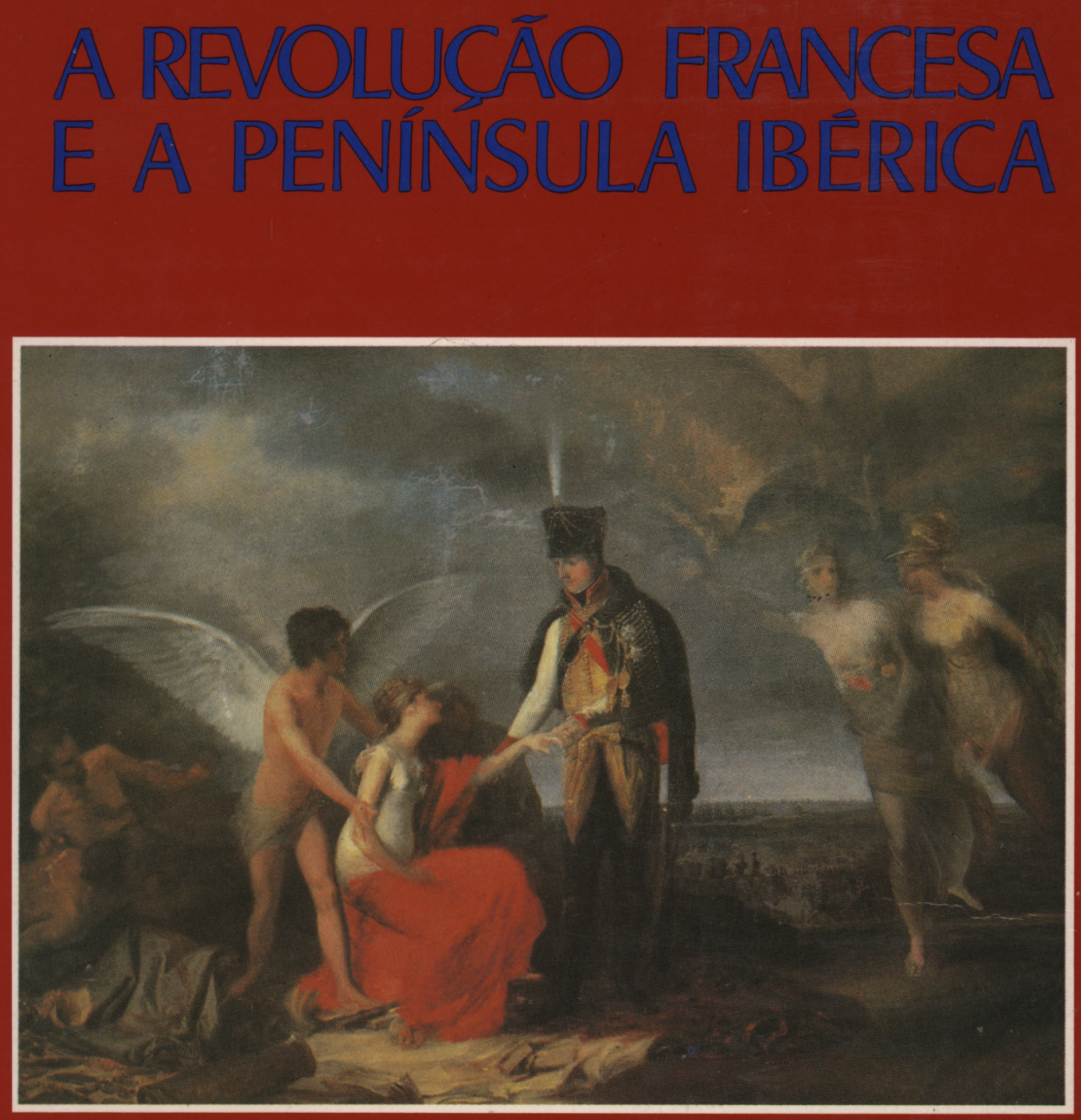

INSTITUTO DE HISTÖRIA E TEORIA DAS IDEIAS FACULDADE DE LETRAS 
MARIO CERUTTI *

\title{
AUTONOMIA REGIONAL Y ESTADO NACIONAL EN MEXICO A MEDIADOS DEL XIX
}

\author{
Santiago Vidaurri y el liberalismo "de la frontera"
} (1855-1864)

1. El siglo XIX emerge en México (y seguramente en otras latitudes, latinoamericanas y aún europeas) como un período que presenta dificultades para hablar de una historia nacional. La impresión más impactante que se sufre al revisar los muy ricos documentos guardados en archivos de provincia, o al recorrer trabajos elaborados por colegas que se nutren en esas mismas fuentes, es que el XIX habría sido, con mayor justeza, un lapso definido por un conjunto de historias, protagonizadas medularmente en ámbitos regionales.

Estos procesos enmarcados regionalmente - sin escapar a la influencia de lo nacional y del contexto mundial - convergieron en un devenir más global, o globalizante, de más fuerte entrelazamiento e interacción entre las diversas historias, cuando comenzó a definirse con mayor vigor el Estado Nacional (el Estado-nación).

Enfrentar el estudio de este período desde el punto de vista metodológico, entonces, obliga a situarse en una perspectiva regional. $\mathrm{Y}$ no sería, ésta, una ocurrencia del investigador, sino una exigencia de los proprios procesos sometidos a indagación.

Con esta advertencia inicial, que quizás haya que tener en cuenta para momentos más contemporáneos, conviene señalar de inmediato ciertos aspectos relevantes del siglo XIX en México y en otras sociedades del continente. Aluden al racimo de tendencias significativas que se perfila y acentúa, sobre todo,

* Facultad de Filosofía y Letras, Universidad Autónoma de Nuevo León (México). Ponencia presentada en el coloquio sobre «El nacionalismo en México», El Colegio de Michoacán, Zamora, octubre de 1986. 
en la segunda fracción de la centuria, para consumarse como situación novedosa y condicionante en las décadas inaugurales del XX.

Enumeramos a continuación algunos de esos aspectos: a) la lenta pero definida aparición del capitalismo, cuyos brotes dispersos y desigualmente situados mostraban la cada vez más fuerte subsunción de la producción al capital; b) el emerger de núcleos burgueses dinamizados por una pujanza que resultó mucho más generosa de lo que con frecuencia evaluaron estudios excesivamente generalizadores, y de lo que ha dado cuenta amplia la investigación realizada en fuentes primarias regionales; c) la articulación e inicial fortalecimiento de un mercado que tiende a convertirse en nacional, fenómeno que se acelera en las décadas primeras del siglo XX sobre la base de los espacios regionales de más vigoroso crecimiento económico; e) conectado con todos estos matices - y con otros que para sintetizar preferimos omitir - se dio el proceso de construcción del Estado Nacional (o Estado-nación), al que brindaremos especial atención en este artículo.

2. Este último aspecto obliga al tratamiento de hechos fundamentalmente sociopolíticos. Su seguimiento permite calificar al XIX como el siglo de la transición entre el derrumbe colonial y la aparición definida del Estado-nación en diferentes lugares de Latinoamérica.

Lo que interesa remarcar por ahora es que la edificación del Estado Nacional fue posible a partir de las relaciones que tejieron, precisamente, los poderes con sustento regional.

En uno de sus puntos críticos, este proceso obligó a que se alcanzaran ciertos acuerdos entre esas formas insulares de dominación. O llevó a que algunas fracciones dominantes regionales alcanzaran suficiente fortaleza como para pasar a constituirse en el nudo de un poder central que sometía al resto de las porciones territoriales que se integrarían - geográfica y políticamente - al Estado Nacional. Es lo que sucedió en aquellos países que devendrían estados nacionales multirregionales (particularmente: Brasil, México, Argentina).

Cuando no hubo posibilidad de acuerdo - ya por la vía del consenso, ya por la de la coerción y de la fuerza militar -, el poder regional se transformó directamente en base política de un nuevo Estado Nacional: los pequeños países centroamericanos, o los casos de Uruguay y Paraguay, en el Sur, son útiles para ejemplificar este tipo de resultados históricos.

La cuestión regional y su estudio, en este sentido, asume una valoración indiscutible si de comprender los grandes procesos del siglo pasado se trata. $\mathrm{Y}$ es bueno recordar, para no 
suponer que la historia latinoamericana es absolutamente específica - aunque esté saturada de especificidades - , que similar planteamiento puede caber para ciertas situaciones europeas (Italia, Alemania) y hasta para Estados Unidos.

3. Antes de comenzar a revisar lo acaecido en México y su noreste, quizás resulte oportuno señalar lo que entendemos por Estado Nacional.

Se trataría de un resultado histórico, de características estructurales (es decir, capaz de mostrarse históricamente en períodos de duración secular), sustentando al menos en estas tres claves: a) un conjunto social, conglomerado que agrupa con frecuencia diversas nacionalidades, culturas y/o razas; b) un territorio que acoge ese conglomerado humano, y que permite distinguirlo en términos internacionales; c) un poder soberano - el Estado - capaz a la vez de sostener la independencia y diferenciación territorial apuntada, y de regular con eficacia dos tipos de relaciones internas: las que se tejen entre los ámbitos regionales unificados en el contexto de aquella geografía, y las sociales (entre clases y sectores de clase potencialmente conflictivos).

Es imprescindible distinguir, pues, entre Estado Nacional o Estado-nación y Estado. Este último no se resume exclusivamente en un puro ejercicio político: es absolutamente indispensable que cuente con un aparato administrativo, apto para ramificarse por todos los rincones del territorio y sobre cada uno de los nudos básicos del conjunto social. Si el poder político no lograba - en el siglo XIX - controlar las aduanas ni sustentar materialmente un ejército lo suficientemente sólido como para someter las milicias locales, si no imponía una legislación general, ni regulaba aspectos como la circulación interior, la moneda y otros instrumentos de uso cotidiano, era impotente para fructificar en un Estado.

Este poder politico y administrativo - además - tendió a transformarse en central y centralizante. Fue en ese momento cuando le fue factible cubrir su misión soberana sobre la sociedad y la geografía. Pero - no debe olvidarse - esto ocurrió cuando fue capaz de representar con coherencia, también, las bases sociopolíticas que lo nutrían. En rigor: a los grupos dominantes de los diversos ámbitos regionales que se articulaban en el Estado Nacional en consolidación.

En síntesis: el Estado emergió como un poder articulado que trató de administrar y orientar al Estado Nacional. Y esa tarea pudo llevarla adelante cuando asumió un carácter repre- 
sentativo para un racimo de intereses regionalmente hegemónicos. Al perfilarse este Estado terminó de diseñarse, finalmente, una alianza entre grupos dominantes que alcanzó influencia nacional.

4. En el caso concreto de México, el proceso de construcción de un Estado Nacional soportó una conyuntura particularmente crítica: la transcurrida entre 1846 y 1867, en la que se concentrará nuestra exposición.

Fue un lapso abierto con la guerra contra Estados Unidos (es decir: cuando se perdió más de la mitad de la superficie heredada de España), a la que siguió la revolución liberal (con sus reformas y la guerra civil) y que se cerró con otra intervención extranjera, esta vez europea.

Podría manifestarse que entre 1846 y la expulsión de los franceses, México vivió su más dramática circunstancia en el camino hacia el Estado Nacional. La derrota frente a Estados Unidos le cercenó una enorme porción de su geografía (anticipada ya con la separación texana). La invasión francesa indicaba la posibilidad de un reordenamiento colonial. Entre las opciones posibles estuvieron, sin duda, el desmembramiento al estilo centro americano e inclusive la desaparición como un Estado Nacional diferenciado.

La explosión liberal fue una respuesta a tan dificultoso panorama. Desde $1854 / 55$, una serie de propuestas radicales se levantaron sobre el territorio que todavía era México. La necesidad de una transformación profunda - desde la perspectiva liberal - no sólo implicaba una visión modernizante del futuro: también, la necesidad de salvar a México como una sociedad asentada sobre un territorio autónomo en el contexto internacional.

¿Qué sucede en el noreste fronterizo en estos años? Es fundamental recordar que se trataba de un nuevo noreste. La pérdida del antiguo septentrión, la flamante línea limítrofe del Bravo transformaron imprevistamente a un conjunto de poblaciones y comarcas en, justamente, fronterizas. Se convirtieron en vecinos directos de un expansivo Estado Nacional - el norteamericano - que mostraba los más altos niveles de crecimiento capitalista. Estaban adheridas a la franja oriental estadounidense que, en esas décadas, era ya el área más desarrollada, y que aceleraría enormemente su desenvolvimiento económico tras la guerra de Secesión (1861-1865).

Fue imperioso, pues, readecuar el funcionamiento de este ámbito regional - que se configuraba básicamente con Coahuila, Nuevo León y Tamaulipas - en un viraje que además 
pretendía marchar a la par de las reformas planteadas en todo México. La coincidência entre ambas tendencias acaeció porque el noreste se convirtió en un bastión - jamás derrotado por los conservadores autóctonos - de la causa liberal.

5. Es con este marco que surge desde Nuevo León un jefe político y militar que impulsaría ese reordenamiento regional: Santiago Vidaurri ( $\left.{ }^{1}\right)$.

Hasta principios de 1855 Vidaurri había ocupado diversos cargos administrativos, y en no pocas ocasiones su tarea llegó a ser la principal en los equipos de secretarios que acompañaron a varios gobernadores. Al rebelarse, entonces, contaba con una prolongada experiencia administrativa y con un conocimiento minucioso de los problemas fronterizos.

Desde que se levantó en armas - en mayo de 1855 se apodera de Monterrey, y pasa luego a controlar Coahuila e influir sensiblemente en Tamaulipas -, el jefe nuevoleonés blandió con firmeza la causa liberal. Pero el matiz - inevitable en esos tiempos - era el siguiente: el liberalismo del noreste colocaba junto a las propuestas globales de esta corriente una densa problemática regional. Se nutría de los dilemas que día a día enfrentaban los pobladores de esta parte de la frontera, y levantaba una clara bandera de autonomía.

Liberalismo, ámbito regional, particularidades locales y exigencias de la vida cotidiana emergían totalmente entremezclados en esta corriente de pensamiento y acción que tuvo a Vidaurri, entre su ascenso al gobierno y el momento en que fue destituido por Benito Juárez, en $1864\left(^{2}\right)$, como figura principal.

(1) Por las características de nuestro trabajo no mencionaremos las fuentes primarias en las que se sustentan sus conclusiones. Para una consulta de ese tipo puede verse Mario Cerutti, Economía de guerra $y$ poder regional en el siglo XIX, Monterrey, Archivo General del Estado de Nuevo León, 1983; "Poder regional, gobierno central y periodidismo liberal en México en años de la Reforma. Santiago Vidaurri y los estados fronterizos del noreste (1855-1864)", en Alberto Gil Novales (comp.), La prensa en la revolución liberal. España, Portugal y América Latina, Madrid, Universidad Complutense, 1983; "Guerras civiles, frontera norte y formación de capitales en México en años de la Reforman, Boletín Americanista, 33, Universidad de Barcelona, 1983; y "Aduanas poder regional y Estado Nacional en México a mediados del siglo XIX", Trienio. Ilustración y Liberalismo, 4, Madrid, noviembre de 1984. Para la elaboración de este artículo se sumó la revisión de material primario efectiada por Rocío González Maiz, especialmente en lo atinente a los intentos de organizar coaliciones de gobernadores realizados desde Monterrey.

(2) Desde mediados de 1863. Benito Juárez comenzó a reiterar una antigua solicitud: que se devolvieran al gobierno federal los in- 


\section{Revista de História das Ideias}

Hasta el momento en que se agudizan las disidencias con Juárez, la adhesión al liberalismo fue plena. Y con planteamientos frecuentemente radicales: la necesidad de que desapareciera o fuese ampliamente depurado el ejército regular, es decir la fuerza armada que servía a intereses conservadores, resultó una solicitud inmediata de Vidaurri; hacia 1858, cuando quedó en claro la notoria vinculación entre la Iglesia y la insurgencia antiliberal, los ataques a esa institución religiosa no solo proliferaron en el periódico gubernamental, sino que se demandó una acción implacable contra quienes se oponían a las transformaciones propuestas.

Un sesgo análogo aparecía en temas tan delicados como el de la soberanía popular, o en el de la organización nacional. Finalmente, un punto en el que la visión liberal surgió con fuerza fue el relativo al comercio. Para estos núcleos del noreste, era menester abrir las fronteras al intercambio internacional: una savia realmente vivificante para el progreso, para acentuar el desarrollo social y para un más eficaz funcionamiento de las zonas de frontera.

El enfoque fue matizado, ya se dijo, por una visión que atendía las circunstancias del ámbito regional. Con problemas que no eran exclusivos de esta franja septentrional, sino de todo el norte oriental (con Chihuahua, Durango y Zacatecas).

Entre sus dilemas vertebrales sobresalía la lucha contra los contingentes de indios seminomadas (apaches, comanches) que azotaban este inmenso territorio adherido a Texas. Los norteños no planteaban la integración de esos grupos - que penetraban desde Estados Unidos, muchas veces escapando a las tropas del vecino - sino su expulsión y - sí cabía - su exterminio. En este sentido, el "problema del indio» era visto y resuelto de manera similar a lo que en esas mismas décadas acaecía en Argentina, Chile o en los mismos Estados Unidos: era el combate entre la civilización y la barbarie, había la urgencia de ganar territorios para un desarrollo que coronaría las ansias de progreso de la cultura civilizadora (que se convertiría en cultura dominante).

Vidaurri encabezó con firmeza esta guerra racial, contra este enemigo a muerte. Una actitud que le valdría el apoyo

gresos de las aduanas fronterizas, en particular la de Piedras Negras (que en ese momento vivía una inesperada prosperidad por la guerra de Secesión norteamericana). Vidaurri se negó terminantemente, en tanto las tropas juariztas subían hacia el norte por la presión francesa. En un clima de extrema agresividad, Juárez obligó al gobernador de Nuevo León - Coahuila a salir del país, y reintegró su atonomía a Coahuila. Vidaurri adheriría posteriormente al Imperio. 
de la magra población fronteriza, y el respaldo de gobernadores de otros estados del norte oriental.

Un segundo dato de la realidad local era la convivencia con Estados Unidos. En más de una ocasión, bandas texanas incursionaron con fines diversos en territorio mexicano. En una ocasión (1855) incendiaron Piedras Negras. Las correrías texanas mantenían en alto el fantasma de renovadas invasiones norteamericanas. El noreste liberal proclamó aquí, también, un papel activo: el de defensor de la integridad territorial de ese Estado-nación que aspiraba a compartir, aunque con su perspectiva teñida por el contexto inmediato.

Las demandas para que se implementaran políticas de colonización (asentamiento de inmigrantes, sobre todo extranjeros), la necesidad de aumentar la demografía en estos espacios vacíos, la urgencia por establecer un diferente orden arancelario y estimular el comercio, y la angustia por recursos que sostuvieran el readecuamiento que los tiempos exigían a la frontera, ce contaban entre las premuras cotidianas para las que no llegaban soluciones eficaces desde el centro.

$\mathrm{Ni}$ liberales ni conservadores estaban en condiciones de plantearlas, quizás por una simple razón: hacia mediados de siglo, particularmente en esta coyuntura, era casi inexistente una verdadera administración central. $\mathrm{Y}$ el peso de todas estas responsabilidades tenía que ser asumido - y resuelto - por los poderes con bases regionales.

Cuando estalló la guerra civil - que se prolonga luego en la ocupación francesa - los problemas se acentuaron. Y fue más profunda, entonces, la intervención de Santiago Vidaurri y sus adeptos en el manejo de la vida local.

6. La respuesta inicial del noreste liberal incluyó la construcción de un ejército nutrido en el contorno más aledaño.

No debe extrañar: el siglo XIX, al menos mientras se transitaba su segundo tercio, se presentó como un lapso en el que la capacidad política dependía con frecuencia del respaldo militar (la historia de estas tropas regionales podría explicar, en buena medida, el proceso de transición hacia el Estado-nación).

Hombre de su época, Vidaurri movilizó y encabezó más de cinco mil soldados, aptos tanto para las luchas civiles como para la más antigua y casi hogareña contienda con apaches y comanches. Con esta fuerza armada, además, se mantuvo alerta a los conatos texanos y hasta luchó contra sus correligionarios 
liberales $\left({ }^{3}\right)$ cuando las disidencias en el seno de esta corriente se agudizaron (es decir: cuando lo que entraba en controversia era la propia autonomía de un orden con sustento en el noreste).

De manera simultánea, Vidaurri incorpora a Coahuila a ese orden. Y procura - aunque infructuosamente - articular la estrategica Tamaulipas. La unión de Nuevo León-Coahuila, y el frustrado intento sobre el vecino oriental, señalaba que el liberalismo vidaurrista ampliaba su perspectiva más allá de los límites de un estado-provincia: apuntaba a una reorganización de un ámbito más extenso, que rebasaba Nuevo León. Es que entendía que los problemas estructurales eran afines a todo este espacio fronterizo. Y porque, probablemente, pretendía desde allí insinuar de qué manera debería organizarse el Estado Nacional.

Este sistema de poder regional - claramente asentado en lo militar - tuvo como eje a Monterrey. Una ciudad que se convertiría en pivote político y de la actividad mercantil del conjunto norestense (aún del mismo Tamaulipas, debido a la aceptación generalizada de arancel Vidaurri). Por ello, Monterrey resultaría la gran usufructuaria de otro cimiento vidaurrista: el empleo del comercio internacional como fuente de recursos, gracias a la cual era factible mantener en alta proporción aquel funcionamiento bélico.

En este aspecto, el uso de la línea de frontera - abruptamente acercada por la derrota frente a Estados Unidos - emergió como un dato clave. Para movilizar un grueso número de batallones - a los que había que armar, montar, vestir y alimentar - se requerían fondos cuantiosos. Ya que el supuesto poder central no era capaz de solventar las necesidades locales - entre otras, la propia guerra - los hombres de la región tomaban a su cargo ingresos que, técnicamente, debían corresponder a una administración federal.

El puente entre comercio y captación de recursos se montó con la monopolización relativa del sistema aduanal fronterizo, al cual se sumaron puestos fundados sobre el Bravo por el mismo Vidaurri.

Hemos detallado con amplitud, en trabajos anteriores, lo atinente a estos hechos: sobre todo porque los documentos revisados verificaban las vinculaciones entre el orden vidaur-

(3) La más graves crisis se planteó con el presidente Comonfort, en 1856, tras la unificación formal de Nuevo León y Coahuila. Con la ayuda de tropas tamaulipecas, Comonfort intentó hacer retroceder a Vidaurri en este punto. No lo logró, y finalmente aceptó la resolución del Congreso de no innovar en la materia. 
rista y la fase inaugural en la formación de capitales en Monterrey. Los mercaderes de la ciudad - a la par de otros del noreste (como Evaristo Madero, por entonces asentado cerca de Piedras Negras) y aún del sur de Estados Unidos - se involucraron sin prejuicios en el aprovechamiento de las necesidades de guerra que soportaba Nuevo León-Coahuila $\left({ }^{4}\right)$.

Al revitalizar o directamente habilitar una seria de puestos aduanales ubicados sobre el Bravo, al pugnar por el control de los puertos marítimos instalados junto al Golfo (Matamoros y Tampico, con escaso éxito sobre todo respecto al último), el poder asentado en Monterrey se adueñó de la más regular y rica fuente de recursos que existía entonces no sólo para México, sino para todo Latinoamérica: la derivada del comercio exterior.

Pero Vidaurri fue más allá: nombró funcionarios, estableció aranceles, vigiló la circulación del metálico (una savia indispensable para los contactos mercantiles con el mercado mundial). En 1856 desconoció la Ordenanza General de Aduanas promulgada por el presidente Ignacio Comonfort, y lenta pero tenazmente - con el apoyo entusiasta de los comerciantes locales y de las poblaciones fronterizas - fue delineando el arancel que llevaría su nombre: llegó a disminuir hasta cerca de un $60 \%$ los recargos a los artículos importados, en comparación con la ordenanza federal $\left(^{5}\right)$. Un aluvión de mercancías entró así por esta franja territorial, para disgusto y enojo de los comerciantes de Veracruz y de la ciudad capital.

Aduanas y aranceles - claros instrumentos de un gobierno central cuando logra imponer su soberanía política y administrativa sobre el Estado-nación - quedaron bajo dominio de un poder capaz de delinear la actividad política social, económica y militar de su ámbito regional.

Con estos recursos - a los que agregaba los que obtenía como préstamos de los grandes comerciantes locales, precisamente - , Vidaurri solventó en elevada proporción sus gastos militares, prestó ayuda a la causa liberal (al menos hasta mediados de 1863), mantuvo bajo su férula a Coahuila, combatió sin cuartel a los grupos seminómadas, estuvo atento a las incursiones texanas, se sumó a la lucha contra los franceses y,

(4) Sobre este punto pueden consultarse Economía de guerra $y$ "Guerras civiles y formación de capitales», citados. También, Mario Cerutti, "Poder estatal, actividad económica y burguesía regional en el noreste de México (1855-1910)», en Siglo XIX. Revista de Historia, 1, Universidad Autónoma de Nuevo León, enero-junio de 1986.

(5) La evolución del arancel Vidaurri ha sido tratado en «Aduanas, poder regional y Estado Nacional», citado. 
no hay que olvidarlo, impidió que entrara a sus dominios - hasta principios de 1864 - el ejército que dirigían los liberales del centro. En el marco de una tumultuosa economía de guerra sustentó una estabilidad política (solo matizada con algunos traspiés derivados de sus disputas con otros liberales) poco común en esos años: casi una década.

Mientras conservadores y otros liberales no lograban afianzarse en muchas de las restantes áreas de la geografía mexicana, Vidaurri se permitía continuar estimulando un proyecto que había patrocinado desde sus años de secretario: una coalición de gobernadores norteños.

El más antiguo e insistente motivo consistía en responder con eficacia a las incursiones indígenas. Pero, estallada la crisis que condujo a la guerra civil, desde Monterrey se señaló que una alianza de este nivel se transformaría en un pilar fundamental para evitar la desintegración que amenazaba a México. Así, si desde el centro del país se consideraba con frecuencia que propuestas de este tipo insinuaban nuevos separatismos, desde el noreste se replicaba que no quedaban demasiadas opciones para salvar a la nación. La alternativa para estructurar el Estado Nacional, el soporte de su integridad territorial, eran las propias provincias, los poderes regionales. En esta la autonomía local no significaba un obstáculo a la configuración del Estado-nación, sino la base de su sobrevivencia $\left(^{\left({ }^{8}\right) \text {. }}\right.$

Este punto define, por último, la idea de organización nacional que presentaba el vidaurrismo. Si era cierto que debía existir un poder central, tendría que caracterizarse por su discreción, por admitir la importancia y peso de las fuerzas del interior del país, por reconocer no sólo sus derechos sino la necesidad de quedarse con recursos que las mismas provincias generaban.

Autonomía, vigorosa y amplia, en el marco de un orden social renovado (quizás llegando a la confederación, más que a la federación), parecía ser la invitación originada en el distante y fronterizo noreste.

7. Proceso nada exclusivo de México, sino muy conectado a la historia toda de Latinoamerica, lo vivido en este ámbito regional cuando el siglo XIX comenzaba su segunda mitad nos ha alejado de los problemas más contemporáneos, muchos de

(6) Durante la guerra con los conservadores, el proyecto de coalición se extendió hacia otros estados (Jalisco. Colima, Michoacán, Sonora y San Luis, entre ellos). Esto podría indicar que la propuesta tenía que ver más con una idea de organización nacional que con un eventual intento de separación territorial. 
ellos considerados en este coloquio. Pero, como se ha planteado en otras ponencias, tal vez para el estudio del México actual sea menester también retornar a un enfoque con mayor concentración en las regiones.

Si algo muestran las indagaciones más recientes sobre el siglo pasado es que, para una más ajustada interpretación de la multiplicidad de realidades que entonces sacudía a México, las miradas globalizantes pueden resultar discutibles, no demasiado eficaces (sobre todo si olvidan beber en fuentes primarias).

$\mathrm{Y}$ si la perspectiva regional se insinúa como inevitablemente útil para auscultar lo que sucedió tras la fractura del mundo colonial, tendría que evaluarse cuanta calidad ofrece para el análisis de situaciones presentes. Aunque el México de 1980 parece estar muy lejos de aquél que preocupaba a Benito Juárez y a Santiago Vidaurri, parte de lo escuchado en este encuentro indicaría que lo regional continúa no sólo vivo, sino que hasta amenaza con retornar a su pasado de rebeldía, de propuestas más autónomas.

De ser esto correcto, el siglo XIX - su historia concreta y el método para abordar su conocimiento - cobraría significación para quienes procuran profundizar en los problemas del aquí y del ahora mexicanos. 